\title{
Clinical Trial Interactive Response Technology Documentation
}

National Cancer Institute

\section{Source}

National Cancer Institute. Clinical Trial Interactive Response Technology Documentation. NCI Thesaurus. Code C115652.

Records pertaining to the interactive response technology used in the clinical trial. 